https://doi.org/10.21670/ref.1810010

Artículos

\title{
El dispositivo necropolítico de producción y administración de la migración forzada en la frontera Estados Unidos-México
}

\section{The necropolitical dispositif of production and administration of forced migration at the United States-Mexico border}

Recibido el 19 de octubre de 2017. Aceptado el 23 de marzo de 2018. Publicado el 22 de mayo de 2018.

*Autor para correspondencia: Ariadna Estévez, correo electrónico: aestevez@unam.mx

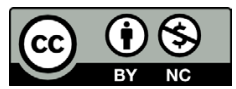

Esta obra está protegida bajo una Licencia Creative Commons Atribución-NoComercial 4.0 Internacional.
Ariadna Estévez a* (iD https://orcid.org/0000-0002-5861-3956

${ }^{a}$ Universidad Nacional Autónoma de México, Centro de Investigaciones sobre América del Norte, México, correo electrónico: aestevez@unam.mx

\section{Resumen}

El objetivo del artículo es argumentar y fundamentar la teoría del dispositivo necropolítico de producción y administración de la migración forzada. El diseño metodológico es deductivo, es decir, se basa en fuentes fundamentalmente documentales mediante las cuales se llegó a dicha teorización. Aun cuando tiene las limitaciones del método, el artículo es innovador porque analiza sistemáticamente fenómenos subjetivos — migrantes, deportados, desplazados y solicitantes de asilo varados o en espera de fallos judiciales que viven en basureros y otros lugares similares- y estructurales - violencia criminal, estatal y sexual, impunidad y megaproyectos económicos- para proponer una teorización de la migración forzada como un dispositivo que operativiza una serie de políticas cuyo fin es administrar la muerte de poblaciones desechables para la reproducción del capitalismo neoliberal, tanto legal como criminal, y las circunstancias políticas y sociales que lo sostienen.

Palabras clave: migración forzada, necropolítica, violencia estructural, violencia criminal, frontera México-Estados Unidos.

\section{Abstract}

The objective of the article is to develop the theory of the necropolitical dispositif for the production and management of forced migration. The methodological design is deductive, that is, it is based on fundamentally documentary sources through which theorization was reached. Even though it has the limitations of the method, the article is innovative because it systematically analyzes subjective phenomena - migrants, deportees, displaced and asylum seekers stranded or awaiting judicial decisions that live in rubbish dumps and other similar pla-

CÓMO CITAR: Estévez, A. (2018). El dispositivo necropolítico de producción y administración de la migración forzada en la frontera Estados Unidos-México [The necropolitical dispositif of production and administration of forced migration at the United States-Mexico Border]. Estudios Fronterizos, 19, e010. https://doi.org/10.21670/ref.1810010 
ces- and structural phenomena - political and sexual violence, impunity and economic megaprojects - to propose a theorization of forced migration as an apparatus that operationalizes a series of policies, the purpose of which is the management the death of disposable populations for the reproduction of neoliberal capitalism, both legal and criminal, and the political and social circumstances that sustain it.

Keywords: forced migration, necropolitics, structural violence, criminal violence, United States-Mexico border.

\section{Introducción}

En la frontera México-Estados Unidos, a los migrantes y poblaciones pobres no solo se les deja morir: son empujados a escenarios de los cuales deben escapar y sobrevivir. En los 10 estados que conforman la frontera (Baja California, Sonora, Chihuahua, Coahuila, Nuevo León y Tamaulipas del lado mexicano; y California, Arizona, Nuevo México y Texas en Estados Unidos) el necropoder expulsa a los migrantes y los pobres a espacios urbanos que son poco propicios para la vida. El fracking, los cárteles de la droga, los feminicidios, las masacres y los asesinatos de autoridades locales, activistas de derechos humanos y ecologistas son las fuerzas necropolíticas detrás el desplazamiento de las poblaciones marginadas. Más aun, los migrantes que se encuentran esperando a que se resuelva su trámite de asilo, o las personas que han sido deportadas y están a la espera de una nueva oportunidad de cruzar al otro lado, son expulsadas a la periferia y otros espacios urbanos donde la vida es apenas posible, lugares tales como tiraderos de basura y coladeras. Asimismo, la violencia criminal, la impunidad y el estado de excepción expulsan a las poblaciones pobres fuera de sus hogares, los cuales se encuentran en geografías ricas en recursos naturales.

La pobreza, la violencia y otras formas precarias de vida de los migrantes y poblaciones marginadas a lo largo de la frontera México-EE.uU. conforman lo que se sugiere llamar el dispositivo necropolítico de producción y administración de la migración forzada, es decir, el conjunto de políticas y leyes ejecutadas para producir situaciones, momentos y espacios que fuerzan a las personas a dejar sus hogares, o las orillan a situaciones y espacios de muerte. Según los informes anuales de la Agencia de las Naciones Unidos para los Refugiados (ACNUR), de 2006 a 2016 un total de 111176 mexicanos y mexicanas han huido del país. El informe de desplazamiento interno internacional más importante, el del International Displacement Monitoring Centre (IDMC) dice que de 2006 a 2014, por lo menos 481000 personas habían sido desplazadas internamente en México. Según el informe, tan solo en 2014, unas 9000 personas fueron desplazadas en 23 eventos masivos en el Estado de México, Sinaloa, Tamaulipas, Chihuahua, Veracruz, Michoacán, Chiapas, Oaxaca, Coahuila y Ciudad de México (IDMc, 2015a; 2015b).

El artículo sugiere que en la frontera el necropoder ejecuta políticas y leyes que deliberadamente intentan conducir hacia la muerte a solicitantes de asilo y deportados, y despoblar espacios geográficamente estratégicos, produciendo más migrantes. Para desarrollar este argumento, primero se examina la idea del necropoder en general y su aplicación en los estudios migratorios; luego se caracteriza el aparato de producción y administración de migración forzada, el cual incluye tres necropolíticas: 
el despoblamiento forzado, el asilo como administración de sufrimiento y los bolsones de desechabilidad.

\section{Entendiendo el necropoder}

Foucault llamó biopolítica a la tecnología de poder mediante la cual se regula y administra la vida de la población como colectivo biológico, con el fin de hacer vivir a unos y dejar morir a otros, generalmente los grupos racializados y subordinados. La biopolítica se refiere a la población como "una masa de seres vivientes y coexistentes que tienen particularidades biológicas y patológicas y que por ello se colocan bajo un conocimiento y tecnologías específicas" (Foucault, 1997, p. 71).

La racionalidad - gubernamentalidad - de la biopolítica contemporánea es el neoliberalismo (Foucault, 1997, p. 67). En el marco foucaultiano, la palabra gobierno no se refiere a la institución de gobierno sino a "una actividad encaminada a conducir a los individuos a lo largo de sus vidas poniéndolos bajo la autoridad de una guía responsable de lo que hacen y lo que pasa con ellos" (Foucault, 1997, p. 67). El neoliberalismo como gobierno se opone a la intervención estatal y a la expansión burocrática en nombre de la libertad económica porque atenta contra los derechos individuales. Su objetivo central es aplicar el discurso económico - conceptos, objetos, lógicas y lenguaje- al análisis social, borrando las diferencias entre los dos campos. El modelo de racionalidad económica se usa para justificar y limitar la acción gubernamental. El gobierno estatal —el Estado gubernamentalizado- se vuelve un administrador de negocios a cargo de universalizar la competencia e inventar sistemas para la acción individual y social, mismos que se rigen por las leyes del mercado. De esta forma la economía deja de ser solo un área de la vida humana para cubrir todas las áreas de esta. Universalizar la economía sirve para entender lo social y evaluar el desempeño estatal y social en términos económicos (Foucault, 2004), con el fin de subordinar todas las esferas a las dinámicas del mercado, incluyendo la economía criminal y los derechos humanos.

Por esta razón los estados neoliberales se han convertido en estados gerenciales que ya no controlan solamente el comportamiento individual a través de la disciplina sino que regulan y administran el crecimiento y la mortandad de la población para la reproducción de sí mismo a través de tecnologías del yo, es decir, técnicas que desplazan al individuo la responsabilidad sobre su propia salud, educación y todo aquello que incide en la reproducción del "capital humano" que cada individuo posee. Para lograr desplazar sus obligaciones sociales al individuo, el Estado neoliberal echa mano de diversas tecnologías de poder, pero aquí las que interesan son dos: la norma y la política pública (Foucault, 2006).

Por un lado, en el neoliberalismo hay una "importancia creciente tomada por el juego de la norma a expensas del sistema jurídico de la ley" (Castro, 2004, p. 219); no es que:

La ley desaparezca o que las instituciones de justicia tiendan a desaparecer, sino que la ley funciona cada vez más como una norma y que la institución judicial se integra más y más a un continuum de aparatos (médicos, administrativos) cuyas funciones son sobre todo reguladoras (Castro, 2004, p. 219). 
Por otro lado, el Estado neoliberal implementa políticas públicas, las cuales se definen como la toma de decisiones del Estado para modificar u orientar la acción social. Toman la forma de elementos legales, políticos y técnicos basados en el conocimiento social (Guendel, 2009, p. 3). En el neoliberalismo se espera que la política pública regule la salud y el crecimiento de la población (Foucault, 1997, pp. 70-71) pero no con intervención estatal directa como ocurría en el Estado de Bienestar sino con políticas encaminadas a que el individuo se haga cargo de sí mismo, o en términos neoliberales, sea "empresario de sí mismo".

El papel del Estado en la política pública neoliberal se caracteriza por una reducción de la política social a un mínimo, y la distribución de beneficios sociales básicos para los pobres, fundamentalmente educación y salud que son los servicios que garantizan la reproducción del "capital humano". Mientras tanto, se incentiva a los sectores sociales más acomodados a usar el sector privado para adquirir servicios de educación y salud. Esta política transfiere a los sujetos la responsabilidad exclusiva de procurar la mejor "inversión" en su capital. En última instancia, el énfasis en el cuidado de sí mismo se presenta como autonomía cuando se conmina a los individuos de la sociedad civil a involucrarse en el diseño de política pública (Foucault, 2004).

Actualmente, en países económicamente subordinados, la administración de las poblaciones para la reproducción del Estado neoliberal pretende, no tanto regular el crecimiento poblacional, sino gestionar la muerte de aquellos que no logran insertarse a la "globalización" o que lo hacen en sus márgenes, como quienes participan en la parte inferior de la jerarquía de la economía criminal. La biopolítica se transforma en necropolítica. Según el filósofo africano Achille Mbembe, toda vez que la pobreza, la desigualdad, la violencia, las masacres, la privatización de la violencia (criminales, mercenarios, guardias privadas) y los mercados por bienes ilícitos que amenazan la vida son fenómenos tan prevalentes que lo que se regula y administra es abiertamente la muerte (Mbembe, 2011). En ese sentido, en un mundo donde la economía de bienes ilegales incluye la vida humana amenazada o en pedazos, su conservación, cuidado y libertad también son una mercancía, y su compra y venta, un mercado (Valencia, 2010). En este escenario la intervención poblacional es para hacer morir a los grupos sociales marginales y dejar vivir a los favorecidos por el neoliberalismo (hombres blancos, ricos, de occidente). Es una administración de la muerte.

En México la necropolítica tiene una particularidad: el Estado comparte sus tecnologías y técnicas de dominación y administración de la muerte con los sujetos de la violencia privatizada — en particular los criminales- dando lugar a lo que se puede denominar la gubernamentalización necropolítica del Estado mexicano o el Estado legal-criminal. Las muestras públicas de violencia extrema, tales como masacres, con el objeto de intimidar, someter cuerpos a tortura, ejecuciones, desaparición forzada, persecución y muerte tienen el objetivo de hacer morir en enclaves territoriales de pobreza, corrupción, impunidad y escasa presencia institucional del Estado, donde el reto es sobrevivir (Estévez, 2013a; 2013b; 2015). Según datos del Centro de Investigación y Docencia Económica (CIDE) y la agencia de noticias viCE, durante el sexenio de Felipe Calderón (2006-2012), se registraron 68 masacres en todo el país (los únicos estados donde no hubo fueron: Zacatecas, San Luis Potosí, Baja California Sur, Morelos, Ciudad de México, Tlaxcala, Puebla, Chiapas y Campeche. En contraste, en Tamaulipas, Chihuahua, Durango y Guerrero fueron los estados donde hubo más hechos, con 11 en los dos primeros casos, nueve en el tercero, y siete en el último (Hernández, 2017). 
Las masacres más impactantes cubiertas por los medios son las siguientes: La Marquesa, Estado de México (2008): 24 albañiles fueron secuestrados y asesinados por presuntos miembros de La Familia Michoacana; Acapulco, Guerrero (2010): un comando armado secuestró a 22 turistas michoacanos de los cuales 18 aparecieron muertos días después; Villas de Salvárcar, Ciudad Juárez, Chihuahua (2010): presuntos sicarios dispararon contra 60 estudiantes entre 12 y 15 años, matando a 16 e hiriendo a 12; Guadalajara, Jalisco (2011): presuntos narcos dejaron los cuerpos de 26 personas en el monumento Arcos del Milenio a unos cuantos días de que comenzaran en esa ciudad los Juegos Panamericanos; Allende, Coahuila (2011): el Ejército irrumpió en las casas del pueblo, quemó los negocios y secuestró a 300 personas que siguen desaparecidas hasta la fecha; San Fernando, Tamaulipas (2011): 72 migrantes fueron asesinados a manos de Los Zetas por negarse a trabajar como sicarios. Asimismo están las masacres cometidas en: Monterrey, Nuevo León (2011): presuntos miembros de Los Zetas irrumpieron e incendiaron un casino donde acribillaron al dueño por no pagar cuota y mataron a 52 con el incendio; Cadereyta, Nuevo León (2014): 49 torsos fueron tirados a lo largo de una carretera; Ayotzinapa, Guerrero (2014): secuestro y desaparición forzada de 43 estudiantes a manos de policías y militares; y Tlatlaya, Estado de México (2014): el Ejército ejecutó a 22 presuntos delincuentes que se habían rendido después de ser acorralados; Tahuato, Michoacán (2015): la Policía Federal ejecutó también a 42 civiles presuntamente criminales que ya se habían rendido; Apatzingán, Michoacán (2015): policías y militares dispararon contra grupos de autodefensa matando a 16 e hiriendo a 44; Zitlala, Guerrero (2015): un comando armado asesinó a siete personas de esa comunidad indígena; y Monterrey, Nuevo León (2016): reos del penal de Topo Chico se enfrentaron en una cruenta riña que dejó un saldo de 49 muertos (Hernández, 2017).

Mbembe (2011) dice que las tecnologías necropolíticas son aquellas técnicas de aplicación de muerte, como el campo de concentración, como en el nazismo, o las masacres rutinarias como las arriba mencionadas. Son necroanatomopolíticas que no simplemente disciplinan los cuerpos, sino que los someten a una destrucción total. Sin embargo, sostengo que la necropolítica igual que la biopolítica opera también a través de tecnologías de regulación de tipo tecnócrata como la norma y las políticas públicas. Las necropolíticas públicas se ejecutan para administrar y regular los efectos adyacentes a la aplicación de muerte, como el sufrimiento social.

\section{El dispositivo de producción y administración de la migración forzada}

Según Foucault, un dispositivo es una red de elementos discursivos y no discursivos tales como leyes, instituciones, infraestructura, con la función específica de mantener el poder. En la era de la gubernamentalidad neoliberal, los dispositivos se caracterizan por ser: incluyentes, ya que tienden a incluir cada vez más elementos; permisivos, pues pueden ser añadidos; y excluyentes pues eliminan aquello a lo que están dirigidos (Foucault, 2006, pp. 66-67).

Giorgio Agamben ha ampliado el concepto de dispositivo diciendo que:

Generalizando ulteriormente la ya amplísima clase de los dispositivos foucaultianos, llamaré literalmente dispositivo cualquier cosa que tenga de algún modo la capacidad de capturar, orientar, determinar, interceptar, 
modelar, controlar y asegurar los gestos, las conductas, las opiniones y los discursos de los seres vivientes (Agamben, 2009, p. 14).

Según Agamben, lo que se encuentra entre un ser vivo y un dispositivo es un sujeto: "Llamo sujeto a lo que resulta de la relación o, por así decir, del cuerpo a cuerpo entre los vivientes y los aparatos" (Agamben, 2009, p. 14).

La producción y administración necropolítica de la migración forzada se refiere pues a cómo la gente que es sujeta a la violencia criminal y legal, a la muerte, el tráfico sexual y laboral, trabajo forzado, y a la economía criminal, se les deja morir en sus países de origen o mientras tratan de cruzar las fronteras que se vuelven cada vez más securitizadas y peligrosas debido a la ilegalización de la migración indocumentada, los obstáculos al asilo y el régimen de deportabilidad (De Génova, 2002). Así, proponemos, el uso de estos dispositivos como herramienta analítica, sugiere que hay dispositivos, tecnologías y mecanismos usados para garantizar que la gente pobre, los marginados y los desechables mueran mientras tratan de migrar.

Los análisis de la gubernamentalidad de la migración se enfocan en cómo las instituciones, las leyes, los centros de detención, las cortes, las organizaciones civiles y otras burocracias se proyectan en diferentes tipos de aparatos que manejan la vida de los migrantes. Estos análisis se enfocan en los dispositivos a través de los cuales los migrantes son construidos, administrados y finalmente expulsados. Mientras que el artículo sigue la estrategia del análisis de la gubernamentalidad neoliberal y sus tecnologías (políticas públicas), lo hace desde una perspectiva decolonial ${ }^{1}$ - el análisis del necropoder- que se enfoca en cómo la gente es empujada a escenarios mortales a través de la gubernamentalidad neoliberal, y cómo esta los fuerza a migrar o permanecer en un limbo de movilidad.

Como en la gubernamentalidad neoliberal del biopoder, el necropoder se ejecuta a través de tecnologías de muerte, necropolíticas. Sin embargo, el propósito de la necropolítica es administrar y regular la muerte más allá de la vida para asegurar la reproducción del capital criminal y legal. Las necropolíticas son tecnologías que pretenden organizar el espacio con base en raza, género y clase. En el contexto de la frontera entre México y Estados Unidos, el dispositivo necropolítico de producción y administración de la migración forzada contiene tres necropolíticas interrelacionadas: a) el despoblamiento forzado, el cual produce solicitantes de asilo, refugiados y los así llamados migrantes indocumentados; $b$ ) el asilo como administración del sufrimiento, el cual utiliza la legislación y las instituciones del asilo para controlar el tiempo y el espacio de los solicitantes de asilo, los refugiados y los migrantes, en vez de proporcionarles protección legal frente a la persecución; y c) los bolsones de

\footnotetext{
${ }^{1}$ La filosofía decolonial es la encargada de desenmascarar la hegemonía europea en el pensamiento mundial. Es de larga data en América Latina y puede remontarse al trabajo del mexicano Leopoldo Zea, el cubano José Martí y el peruano José Carlos Mariátegui, entre otros. Sin embargo es hasta la década de 1990 que los exponentes de este pensamiento se establecen como el Grupo Modernidad/Colonialidad y se imponen la tarea fundamental de descolonizar la epistemología eurocéntrica. Los principales exponentes del pensamiento decolonial son Edgardo Lander, Enrique Dussel, Arturo Escobar, Michel Rolph Troullot, Walter Mignolo, Aníbal Quijano, Fernando Coronil, Ramón Grosfoguel, Santiago Castro Gómez, Catherine Walsh, Nelson Maldonado Torres, Zulma Palermo, Eduardo Restrepo, Agustín LaoMontes, Freya Schiwy y Javier Sajinés. Este es un grupo fundamentalmente masculino que solo se plantea el racismo y la identidad indígena como determinantes de la subjetividad particular de América Latina. Existe un ala feminista decolonial que plantea las particularidades raciales y étnicas de las mujeres latinoamericanas que las desligan de una idea homogenizante de "la mujer". Entre las feministas decoloniales se encuentran Julieta Paredes, María Lugones, Silvia Rivera Cusicanqui y Yuderkys Espinosa.
} 
desechabilidad, que son los sitios de muerte espacialmente definidos en los cuales los solicitantes de asilo, migrantes y deportados son confinados cuando el asilo como aparato de administración del sufrimiento falla en su contra.

\section{Despoblamiento forzado de fronteras}

La violencia criminal fuerza a las personas a irse de México y refugiarse en Estados Unidos; o al menos esa es la narrativa más recurrente: la delincuencia organizada y el narcotráfico han llevado a que México tenga una de las tasas de homicidio más altas en el mundo y por ello muchos huyen del país. México se encuentra en la posición número 23 de los países más peligrosos y está atravesando por una crisis humanitaria (The United Nations High Commissiones for Refugees [UNHCR], 2016). Según la Organización de las Naciones Unidas y el IDMC, los criminales son los responsables (IDMC, 2015a; 2015b); sin embargo, este argumento ignora dos factores. Primero, México es rico en recursos naturales, incluyendo metales (acero, plomo, oro, níquel, zinc y plata) e hidrocarburos (shale gas) (Sinnot, Nash y De la Torre, 2010). En segundo lugar, no toda la violencia de la región está relacionada con los cárteles: incluye feminicidio, asesinatos de activistas por el medio ambiente y asesinatos políticos y desapariciones forzadas (Comisión Interamericana de Derechos Humanos [CIDH] y Organización de los Estados Americanos [OEA], 2015). La violencia criminal, aun cuando es rampante, solo es parte de un peligroso coctel que sirve para "limpiar" áreas donde las comunidades locales se resisten a la desposesión. Esto es lo que se puede denominar despoblamiento forzado.

Según el IDmC, de los 287000 desplazados por la violencia y los 91000 desplazados por desastres en México, la mayoría se encuentra en estados tales como Chihuahua, Nuevo León, Tamaulipas, Sinaloa, Durango, Michoacán, Guerrero y Veracruz (IDMC, 2017). Todos estos estados son ricos en minerales, recursos no renovables y shale gas. Estos estados son famosos también por su violencia relacionada al nacrotráfico. Un número significativo de desapariciones forzadas en las que el ejército y las bandas criminales se encuentran conjuntamente involucradas han ocurrido en zonas de la frontera con EE. UU. (Comisión Nacional de Derechos Humanos [CNDH], 2016). Por mencionar un ejemplo, Ciudad Juárez, Chihuahua (frontera con El Paso, Texas), fue la ciudad más violenta entre 2009 y 2010 (Ortega, 2010). Nuevo León, Coahuila y Tamaulipas son estados controlados por Los Zetas (que son responsables de miles de las 300000 desapariciones forzadas) y por el Cártel del Golfo, cuyos líderes son protegidos por políticos locales (Martínez, 2013).

Estos estados están ubicados también arriba de una fuente de gas shale muy importante en la colindancia entre México y Texas denominada Eagle Ford Shale Basin, en Estados Unidos, y Cuenca de Burgos en el lado mexicano (Lallanilla, 2015). El fracking, método usado para extraer este shale gas tiene consecuencias ambientales importantes ya que requiere del uso de entre 7.6 a 15 millones de litros de agua por extracción y también involucra el uso de químicos contaminantes (Navarro y Bessi, 2015). La explotación de shale gas en Eagle Ford requiere de 27000 pozos, y en una zona árida donde el agua ya es escasa, el uso intensivo del líquido natural está dañando la agricultura y provocando más y más protestas (Grillo, 2014). ¿Quiénes son las víctimas de la violencia en estos territorios ricos en recursos codiciados 
por corporaciones criminales y legales? Según un reporte especial de la Comisión Nacional de los Derechos Humanos (CNDH), la mayoría de los desplazados en México son campesinos de comunidades con economías autosustentables, activistas del medio ambiente y derechos humanos, pequeños propietarios, autoridades locales y periodistas. La mayoría de estos grupos representan una amenaza a los intereses del capital extractivo que quieren apropiarse de sus tierras, ya sea a través de la resistencia explícita (en el caso de activistas, autoridades no alineadas al capital y campesinos), o denuncias (en el caso de campesinos). De esta manera mientras que los cárteles con su violencia ciertamente representan un problema importante en México que no debe ser soslayado, existe un vínculo entre todas las estrategias despobladoras para revelar el papel de las corporaciones trasnacionales, élites políticas y oligarquías económicas en el diario desplazamiento y producción de espacios de muerte en la región (CNDH, 2016).

Los datos indican que en países ricos en recursos naturales la coincidencia entre desplazamiento forzado y violencias criminal, misógina y política no es casual. Esta combinación asesina refleja una política de desplazamiento forzado que tiene el fin de lograr la explotación de recursos libre de conflicto, pues estos recursos son cada vez más valorados en la economía global tales como las industrias de las nuevas tecnologías y de recursos renovables o energías limpias. Para ejecutar esta estrategia, una gran variedad de actores armados -incluyendo narcotraficantes y criminales pero también mercenarios, guardias de seguridad privada y sicarios- venden su expertise en el manejo de tecnologías de muerte a entidades poderosas tales como gobiernos represivos o corporaciones trasnacionales (o las dos) en lo que Mbembe (2011) ha denominado el "gobierno privado indirecto".

Esto es necropolítica - la política de muerte- que Bobby Banerjee llama necrocapitalismo, o las muertes propiciadas por el lucro económico. Para Banerjee, la necropolítica — que define como "las prácticas de acumulación en contextos (pos) coloniales a manos de actores económicos específicos... que involucra desposesión, muerte, tortura, suicidio, esclavitud, destrucción de hábitats, y la administración general de la violencia" - "es una nueva forma de imperialismo. A la expulsión forzada de campesinos le sigue el control de recursos naturales que alguna vez poseyeron" (Banerjee, 2008, p. 15), y esto es lo que encontramos en la migración forzada que se da en México.

Esto tiene relación directa con lo que Rodríguez Garavito denomina "campos sociales minados", es decir, los territorios de pueblos indígenas que son ricos en recursos naturales y están disputados lo mismo por las trasnacionales que por los grupos criminales y los Estados; son minados por poseer recursos y por peligrosos. Allí es donde se promueve el derecho a la consulta previa, que es un mecanismo jurídico que sirve para legitimar con una supuesta consulta la decisión ya tomada de explotar esos territorios (Rodríguez, 2012, pp. 5-6). Porque seamos honestos ¿por qué negociar con comunidades indígenas pobres que se encuentran en reservas ricas en petróleo, agua, minerales e hidrocarburos si pueden ser expulsadas de sus tierras ejecutando indirectamente la violencia a través de actores privados movidos por causas económico-criminales o misóginas?

Mientras que cada país latinoamericano que sufre altos niveles de homicidio también posee minerales y metales preciosos e hidrocarburos, para los propósitos del argumento del despoblamiento forzado la extracción de hidrocarburos a lo largo de la frontera sirve como ejemplo de cómo el desplazamiento forzado, la represión 
política y la violencia criminal y misógina en territorios ricos en recursos coinciden espacialmente. Otros académicos ya han establecido esta conexión entre asesinatos, desapariciones forzadas, feminicidios y desplazamiento forzado, por un lado, y extracción de gas por el otro (Correa-Cabrera, 2015).

Guadalupe Correa, por ejemplo, ha dicho que en el caso de Coahuila y Tamaulipas, la violencia ha sido producida por las élites para forzar a las corporaciones a alquilar seguridad privada. Correa-Cabrera dice que hay una coincidencia espacial entre flujos globales y la desigualdad económica. En esta área en particular hay por lo menos cuatro de estos flujos: la industria maquiladora, la industria extractiva, migración y la delincuencia trasnacional. El impacto de estos fenómenos ha llevado al incremento de la desigualdad en el ingreso en la región ya que sus dinámicas internas amplían la brecha entre ricos y pobres mientras que refuerzan la desigualdad social (CorreaCabrera, 2015).

Por su parte, en el libro Capitalismo de la Guerra contra las Drogas, la periodista Dawn Paley dice que el conflicto interno y la militarización ocurren en espacios geográficos clave para los proyectos energéticos y extractivos. Su trabajo de campo en Colombia, Guatemala y Honduras indica que estos fenómenos también coinciden con la oposición sociopolítica a megaproyectos tales como extracción y explotación de petróleo, agricultura a gran escala, proyectos hidroeléctricos y maderas preciosas. La conexión entre la guerra contra las drogas, la violencia paramilitar y la extracción de gas no son raras porque los actores no estatales las usan para intimidar a sus oponentes y controlar geografías ricas en recursos naturales (Paley, 2014).

De acuerdo con esta evidencia y sus diferentes interpretaciones, se puede concluir que el desplazamiento forzado no es daño colateral sino el resultado deseado - que no intencional - para el despoblamiento forzado de estas geografías. Sin embargo, el Estado no se encuentra solo en esto. Las corporaciones están involucradas activamente aunque de forma tácita, apoyando la violencia, ya que les permite argumentar que la inversión en esas regiones es demasiado cara como una forma de ocultar sus verdaderos intereses. Ultimadamente, estos actores corporativos permiten a los criminales hacer las extracciones por ellos.

\section{Asilo como administración del sufrimiento}

Una vez que las personas son expulsadas de sus casas y piden asilo en Estados Unidos enfrentan el dispositivo de administración del sufrimiento, es decir, la serie de dispositivos necropolíticos diseñados para controlar el espacio y el tiempo de los sujetos. Según Kleinman, Das y Lock (1997) el sufrimiento social agrupa condiciones generalmente categorizadas y estudiadas por separado y de forma individual —violencia, drogadicción, síndrome de estrés postraumático, depresión-y sirve para vincular los problemas personales con problemas sociales evidenciando así que el sufrimiento es una experiencia social que aqueja a países ricos y pobres, pero que afecta primordialmente a las clases marginadas y desposeídas.

Para Kleinman et al. (1997), los poderes de dominación elaboran diversas intervenciones tecnológicas para "tratar" el sufrimiento social, mismas que intensifican el sufrimiento debido a sus efectos morales, económicos y de género, y a que terminan normalizando patologías sociales o patologizando la psicología del terror. Estas 
políticas transforman las expresiones locales de las víctimas en lenguajes profesionales universales de queja y restitución — como el de derechos humanos-, lo cual rehace las representaciones y experiencias de sufrimiento, induciendo a la intensificación del sufrimiento mismo. Das llama a esto la "apropiación judicial y burocrática del sufrimiento" (Das, 2008). La burocratización del sufrimiento social tiene el objetivo de manipular el tiempo de las víctimas pues la espera es una dimensión simbólica de la subordinación política (Auyero, 2013). La vida de los que sufren acontece en un tiempo orientado por agentes poderosos, en una dominación que "se vive como un tiempo de espera: esperar con ilusión primero y luego con impotencia que otros tomen decisiones, y en efecto rendirse ante la autoridad de los otros" (Auyero, 2013, p. 18).

El conjunto de necropolíticas públicas que se apropian del sufrimiento para burocratizarlo, para dominar al otro simbólicamente a través de la espera es lo que constituye los dispositivos de administración del sufrimiento. Los dispositivos para la administración del sufrimiento construyen sujetos que les son funcionales y conjuntan diversos tipos de necropolítica pública —comités y comisiones especiales, reglamentos, unidades de atención a víctimas- que operan a través de tecnologías que regulan la agencia política. La primera es la complejidad interinstitucional. Se conjuntan representantes de los poderes ejecutivo y legislativo en comités o consejos en los que las organizaciones pueden o no tener representación, pero que sirven de foros de colaboración sin influencia real. Este andamiaje interinstitucional echa a andar un complejo juego de trámites burocráticos que dan al sujeto la ilusión de que están avanzando hacia la justicia aunque esté ausente el Poder Judicial y la característica fundamental sea la espera, y como dice Auyero:

La espera produce incertidumbre y arbitrariedad. La incertidumbre y la arbitrariedad engendran un efecto subjetivo específico entre quienes necesitan al Estado para sobrevivir: se someten en silencio a requisitos del Estado por lo general arbitrarios. Para decirlo claramente, la dominación política cotidiana es eso que pasa cuando aparentemente no pasa nada, cuando la gente "solo espera" (Auyero, 2013, pp. 36-37).

La segunda es la subjetivación. Las necropolíticas públicas construyen a un sujeto pasivo, ese que es sujeto de intervención para gestionar "positivamente" su sufrimiento y agencia política a través de la "apropiación judicial" de su sufrimiento (Das, 2008). Los sujetos se convierten en objetos de intervención gubernamental que solo esperan, y "la exposición habitual a largas horas demoras modela un conjunto particular de comportamientos sumisos" (Auyero, 2013, p. 25). Esto tiene implicaciones para la subjetividad política como se verá más adelante.

El sistema de asilo en Estados Unidos puede considerarse un dispositivo de administración del sufrimiento no solo porque tiene el fin de controlar a los solicitantes de asilo en tiempo y espacio - no se pueden mover entre lugares mientras esperan el fallo del juez- sino también porque se conforma de todas estas necropolíticas. Como ya se dijo, en la biopolítica y la necropolítica la ley ya no sirve a la justicia sino que es usada para homogenizar poblaciones. En este caso, hay elementos que son abiertamente administrativos en el ejercicio de la ley que muestran cómo los instrumentos de administración de justicia internacional — la protección contra la persecución- se usan para la regulación de la inmigración en Estados Unidos.

Hay aspectos abiertamente administrativos y procedimentales del ejercicio del derecho de asilo que muestran cómo algunos instrumentos que deben ser para 
la administración de la justicia internacional —tales como la convención sobre refugiados que se refleja en el Acta de Inmigración y Nacionalidad (INA, por sus siglas en inglés) - se usan para administrar la migración forzada y el sufrimiento de los sujetos que huyen. Las tácticas administrativas facilitan el control de la migración de diferentes formas. Primero, la división del sistema en procedimientos afirmativos y defensivos, y el carácter semijudicial de la administración migratoria, lo que deja un amplio margen para decisiones aún más subjetivas y arbitrarias de lo que se espera en el derecho anglosajón, en el que el rol del juez y la jurisprudencia es más importante que las leyes derivadas de la Constitución. Esta división permite un trato diferenciado de los solicitantes de acuerdo con criterios de clase y de género.

Por un lado, los solicitantes en procedimiento afirmativo son los que ingresan al país con visa, o que con una visa que se venció o que no les da permiso de trabajar están dentro del país y no han sido puestos en procedimientos de deportación. Estas solicitudes son revisadas por un oficial de la us Office of Immigration and Citizenship Services (USCIS), quien si no la aprueba las refiere a un juez de migración de la Executive Office for Immigration Review (EOIR), para revisión judicial. Según Kurzban: "Las solicitudes que han sido interpuestas primero frente al oA (Oficial de Asilo) se llaman 'solicitudes afirmativas' porque no se interponen en procedimiento de remoción en el sentido de 'defensa' frente a la remoción" (Kurzban, 2014, p. 698).

Por otro lado, este es el momento en el que el caso se convierte en defensivo. El solicitante ve a un juez en una corte de inmigración como parte de los procedimientos de remoción, de allí que se llame "procedimiento defensivo". Las cortes migratorias son instancias administrativas que resemblan cortes. Según Anna Jessica Cabot, coordinadora legal de Las Americas Immigrant Advocacy Center, en El Paso, Texas, las cortes migratorias son:

Algo que es como una corte, son de hecho órganos administrativos, y estos dicen ok, los beneficios de la migración son tales que debemos darle a la gente un lugar que parece una corte para asegurar primordialmente que sus derechos puedan ser apelados en esta área (Cabot, 2012).

Aunque las cortes migratorias son cuerpos administrativos que parecen cortes, la aplicación de la ley en ellas es aún más subjetiva que en las cortes penales y civiles, entre otras cosas porque dan poca protección constitucional, una protección que según los antecedentes jurisprudenciales se restringen al debido proceso, en acuerdo con la $5^{\mathrm{a}}$ enmienda, que se refiere a las personas más que a los ciudadanos; y la libertad de expresión, según la $1^{\text {a }}$ enmienda, la cual permite que los no inmigrantes sean miembros de partidos comunistas y anarquistas (Rafeedie vs INs 1992, en Kurzban, 2014, p. 159). De hecho, dice Cabot, la ley:

Puede ser cambiada de acuerdo al juez que sirve en cada corte... cada juez puede alterar las reglas dentro de su propia corte y esto les da poderes discrecionales mucho más amplios que a los jueces en otras cortes en Eu, cortes criminales, civiles... para cambiar las reglas que van de acuerdo a sus prejuicios y preconcepciones que hacen en otras arenas (Cabot, 2012).

En cuanto al procedimiento defensivo, estos fueron establecidos en la Illegal Immigration Reform and Immigrant Responsibility Act (1996), la cual impone la remoción o deportación inmediata de personas sin documentos. Los migrantes indocumentados en la frontera o aquellos a los que un oficial de migración (OM) les 
niega el estatus de refugiado se les deporta de manera sumaria a menos que pidan asilo ante un juez. Los migrantes indocumentados pueden pedir asilo y expresar un miedo fundado de persecución ante un om que determina si la persona tiene o no un "miedo creíble" de persecución. Si el solicitante prueba tener un miedo creíble de persecución puede obtener un permiso humanitario de permanencia mientras su estatus legal se resuelve (parole), después de probar identidad, probabilidad de presentarse a las audiencias y no representar una amenaza a la seguridad interna de EU. Si no se prueba el miedo creíble, los solicitantes pueden pedir una revisión que toma hasta siete días, tiempo durante el cual permanecen detenidos.

Si se comprueba el miedo creíble, esta vez van frente a un juez a una audiencia en la que piden asilo, detención de la remoción o protección bajo la Convención contra la Tortura (Kurzban, 2014, pp. 181 y 698). Si no, los solicitantes permanecen en detención hasta que tengan su audiencia que puede tomar mucho tiempo en programar. Aunque el tiempo de detención no es estandarizado en todos los Circuitos, hay precedentes en la mayoría de los mismos que establecen que ser detenido por un tiempo "razonable" no pueden ser "años", como ha ocurrido en casos en los que algunos solicitantes han permanecido en detención hasta 4.5 años. En ese caso en particular, el $9^{\circ}$ Circuito resolvió que lo que se considera un "tiempo razonable" no podía ser mayor a seis meses (Nadarajah vs González, citado en Kurzban, 2014).

El éxito de la entrevista de miedo creíble depende totalmente de la percepción del juez. Esta prerrogativa también se encuentra en la REAL ID Act (1996) que le da a los jueces la:

Decisión de credibilidad negativa, con la cual puede decidir que las historias de los solicitantes no son creíbles, basado solo en inconsistencias en la historia, incluso inconsistencias que no tienen que ver con el fondo de la solicitud, como el color de la casa, la hora del día en que algo ocurrió, etc. Esta clase de juicio subjetivo es insuficiente para que el juez descarte el testimonio del reclamante (Cabot, 2012).

Cabot asegura que también inconsistencias como esa son muy frecuentes en el caso de los mexicanos solicitando asilo, dado que:

No han visto a un abogado, y también muchas personas huyen hacia la frontera, textualmente corren a la frontera, conocemos gente a la que le han disparado y son llevadas al hospital tan pronto cruzan, así que las limpian, las drogan y las ponen en analgésicos y las mandan de regreso a la frontera para su entrevista, están bajo el efecto de analgésicos fuertes apenas horas después de haber sido heridos de bala, y dicen cosas que son apenas consistentes con las cosas que pueden decir en el futuro, pero su testimonio se descarta (Cabot, 2012).

Luego Cabot confirma que esto es un factor determinante en el rechazo de la solicitud, porque:

Si tienes a un juez con la noción preconcebida de que los mexicanos no merecen el asilo, y con el poder de decidir que su historia no es creíble solo con base en cosas pequeñas, entonces es increíblemente fácil para ese juez solo decir que su testimonio no es creíble (Cabot, 2012). 
La defensora de derechos humanos del bufete Southwest Asylum \& Migration Institute (sAMI), Crystal Massey (2012) dice que al menos en el caso de los mexicanos, la división entre procedimiento afirmativo y negativo sirve como su propio filtro, para ver quién puede entrar al sistema de asilo como inmunización contra la violencia criminal, lo cual no significa que lo obtengan solo por ello. Massey (2012) asegura que la gente que tiene una visa es generalmente de clase media, mexicanos(as) bien informados que tienen los medios o el conocimiento para obtener documentos que les permiten cruzar fronteras, o saben que al expresar en la frontera su interés de pedir asilo los puede poner en detención temporal. Massey cree que los hombres jóvenes pasan más tiempo en detención porque son quienes están asociados con el negocio de la droga o las pandillas. Durante la detención las personas son maltratadas, ya que se les fuerza a permanecer en condiciones degradantes o incómodas durante periodos largos; o son intimidadas para presionarlas a desistir de su demanda de asilo - se separa a los niños pequeños de sus padres y se les dice que pueden permanecer separados por mucho tiempo- - Otra táctica que se utiliza para prevenir el acceso al sistema de asilo es el tiempo, ya que no se puede solicitar asilo después de tener un año dentro de territorio estadounidense. Los solicitantes meten su solicitud (forma I-589) junto con su testimonio y la evidencia que la sustenta durante los primeros encuentros con los jueces, en sus audiencias maestras. Dado que los jueces llevan muchos casos, existe un atraso de dos años - algunos solicitantes que llegaron en 2012 tuvieron sus audiencias hasta 2014-. Según Ileana Holguín, abogada y Directora Ejecutiva del Diocesan Migrant \& Refugee Services, Inc. En El Paso, Texas, la revisión de los casos es más rápida en la corte de detención ya que estos centros son privados y el gobierno tiene que pagar por cada solicitante detenido, así que los apuran para ahorrarse dinero (Holguín, 2012). Sin embargo, muchos casos se pierden porque las personas no reciben ningún tipo de asesoría legal o no saben de la prohibición después del año. Holguín (2012) dice que los jueces están enterados de esta situación y tienen mayor disposición a apresurar los casos, e incluso se han comprometido a revisar tres casos en tres horas y media, algo que también indica que ya saben en qué sentido irá su decisión.

\section{Bolsones de desechabilidad}

El 27 de enero de 2017, el presidente Donald Trump emitió una orden ejecutiva sobre migración que no solo prohibía la entrada de ciudadanos de siete países árabes sino que dio un golpe histórico al asilo y al sistema de refugio en general. La orden suspende admisiones generales de refugiados por 120 días y admisiones de sirios hasta nuevo aviso, y puso un límite de 50000 a las admisiones anuales (Obama aceptaba 150 000). Aunque la orden impone retos legales importantes a aquellas personas que procesan solicitudes de asilo, hay consecuencias sociales y humanas importantes que son poco evidentes por las implicaciones de esas medidas. Una consecuencia importante es la emergencia de lo que se denomina bolsones de desechabilidad, que se refiere a las personas que se quedan en tiraderos de basura a cielo abierto a esperar a que les caiga algún trabajo informal, o en las coladeras del drenaje y los alrededores de albergues improvisados de migrantes. Un número indeterminado de bolsones de desechabilidad se pueden encontrar en la ciudad fronteriza de Tijuana, la cual se encuentra cerca de 
la ciudad fronteriza de San Diego, California. Miles de solicitantes de asilo y migrantes han quedado atrapados en Tijuana desde que la orden ejecutiva fuera girada porque estaban esperando a que su trámite de asilo fuera procesado.

A principios de febrero de 2017 se hizo una visita a los albergues de migrantes para documentar esta crisis humanitaria, donde había el tipo de migrantes digamos esperado: mujeres mexicanas huyendo de los cárteles y de violencia de género, así como guatemaltecos, hondureños y salvadoreños huyendo de la violencia de pandillas en su región. Pero había también el tipo de migrante no tan esperado: haitianos que buscaron refugio en Brasil después del terremoto de 2010 en su país pero que han abandonado Brasil por la crisis económica y política, la cual ha reducido dramáticamente las probabilidades de empleo. Estos haitianos no son necesariamente los típicos migrantes "económicos"; muchos son ingenieros, médicos y arquitectos cuyas edades van de los 20 a los 30.

De hecho, este pequeño grupo compone la mayoría de los atrapados en Tijuana. Según la activista Soraya Vázquez (2017), del Comité Estratégico de Ayuda Humanitaria Tijuana, seis haitianos llegaron a Tijuana el 23 de mayo de 2016. El siguiente día había 100; dos meses después había 15000 y al final de 2016 había unos 30000 haitianos atorados en Tijuana provenientes de Brasil, aunque a través de una red de tráfico que Vázquez dice que no ha sido documentada. En comparación, unos 10000 sirios pidieron asilo en Estados Unidos en el mismo periodo. Los solicitantes de asilo no pueden trabajar, no tienen residencia permanente, y si son haitianos con frecuencia no hablan español. Sin embargo, deben mantenerse a ellos mismos y sus familias mientras esperan a que los oficiales de migración procesen sus solicitudes. Por si fuera poco, han perdido toda posibilidad de establecerse en Estados Unidos después de que el presidente Donald Trump determinara poner fin al Estatus de Protección Temporal que su antecesor Barak Obama había aprobado después del terremoto de 7 grados que azotara la isla caribeña en 2010. En mayo de 2017 se extendió por seis meses más, pero en enero de 2018 se determinó ponerle fin y darles 18 meses a los haitianos para dejar Estados Unidos o ser deportados en julio de 2019.

Estas personas viven en Tijuana en tiraderos a cielo abierto, coladeras y albergues improvisados. Muchos buscan trabajos manuales en el mercado negro, limpiando casas y oficinas, trabajando en maquilas o entregando pizzas por sueldos miserables. Toda esta situación en la frontera recuerda lo que Henry A. Giroux llama la "maquinaria de desechabilidad" (machinery of disposability): "Lo que ha emergido en esta nueva coyuntura es una intensificación de la práctica de desechabilidad en la que más individuos y grupos son considerados como un exceso, consignados a zonas de abandono, vigilancia y encarcelamiento" (Giroux, 2014, párr. 2).

La gente forzada a huir de desastres naturales y violencia inimaginable en sus países de origen se vuelve desechable; las personas son desperdicios humanos en los tiraderos y drenajes, en la puerta de entrada a una de las naciones más ricas. De esta forma la gente está confinada a espacios sociales definidos por lo que Edward W. Soja llama la "organización política del espacio", pero con la muerte como meta principal. La idea de Soja de la (in)justicia espacial establece que la riqueza y la pobreza son distribuidas geográficamente según las líneas de clase, raza y género (Soja, 2009). Estas fuerzas determinan lo que llama "localización discriminatoria", la cual es creada "por medio de prejuicios impuestos sobre ciertas poblaciones debido a su localización geográfica", y es "fundamental en la producción de la injusticia social y en la creación de estructuras espaciales de privilegio y ventaja" (Soja, 2009, p. 3). Soja cree que "la 
organización espacial... es una fuente particularmente poderosa de injusticia espacial" (Soja, 2009, p. 3).

Mientras que sus ejemplos van del apartheid, la segregación residencial y la militarización, creo que las fronteras nacionales, tales como las que dividen a Estados Unidos de México, son espacios importantes de injusticia debido a la desigualdad económica y la proliferación de proyectos económicos tales como la construcción de carreteras y actividades mineras. Soja dice que:

Geográficamente el desarrollo desigual y el subdesarrollo proporciona otro marco de interpretación para procesos que producen injusticias, pero como con otros procesos, solo es cuando esta desigualdad se solidifica en estructuras más durables de privilegio y desventaja que la intervención se vuelve necesaria (Soja, 2009, p. 3).

Los bolsones de desechabilidad son entonces áreas de injusticia espacial en las que poblaciones vulnerables, especialmente las de migrantes, son forzadas a vivir en condiciones inhumanas y mercados laborales ilegales con una aprobación tácita del gobierno que debería, en teoría, y bajo la legislación de derechos humanos, ser protector. Es una versión radicalizada y espacializada de lo que los sociólogos llaman "bolsones de pobreza", es decir, los barrios en los que los extremadamente pobres tienden a ser confinados en guetos, incluso en la medida en que la prosperidad crece alrededor de ellos, y están surgiendo no solo en Tijuana sino a lo largo de la frontera norte de México gracias a la represión de Estados Unidos.

\section{Conclusiones}

El artículo propone que en la frontera México-EE. uU. hay una política deliberada de forzar a la gente a dejar sus casas a través del uso de diferentes tecnologías de muerte. Llamo a esto el dispositivo necropolítico de la migración forzada. Esta producción confía en ambos aparatos y aplicación de la ley que deliberadamente produce muerte, ilegalidad y violencia criminal para lograr su meta de despoblar, desposeer y administrar a los pobres al tiempo que producen migración indocumentada y solicitantes de asilo. Para desarrollar ese argumento el artículo primero examinó la idea del necropoder, que sugiere que en el tercer mundo el poder sobre la muerte es más común que el poder sobre la vida. Luego se explicó la idea del dispositivo como la tecnología de poder que contiene diferentes discursos cuyo fin es administrar y conducir la conducta de sujetos. El dispositivo necropolítico de la migración forzada comprende tres necropolíticas: despoblamiento forzado, asilo como administración de sufrimiento y los bolsones de desechabilidad.

Esta interpretación analítica de lo que ocurre en la frontera en materia de migración forzada es de suma importancia porque aporta al debate en al menos tres sentidos. Primero, expone un elemento estructural a una discusión que frecuentemente se queda en la parte subjetiva o administrativa. La explicación causal de la migración forzada desde una perspectiva de la administración gerencial de la muerte permite ver la variedad de actores que participan en persecución y desplazamiento y propone que el interés aun cuando puede ser aparentemente criminal, no siempre es así de simple pues hay una gran diversidad e intereses económicos legales e ilegales. Segundo, 
propone una conceptualización de las causas de la migración forzada y propone verla como un proceso deliberado - una producción- de expulsión de individuos y conglomerados humanos para garantizar espacios libres de conflicto, o eliminación de grupos de personas desechables en la visión neoliberal. Y por último, plantea los mecanismos administrativos y judiciales de asilo como norias burocráticas que sirven al dispositivo de migración forzada, en vez de garantizar protección a quienes sufren de persecución; no hay intención de proteger a las víctimas, sino de contener una nueva migración forzada.

\section{Referencias}

Agamben, G. (2009). What Is an Apparatus? and Other Essays. California, Estados Unidos: Stanford University Press.

Auyero, J. (2013). Pacientes del Estado. Buenos Aires, Argentina: Eudeba.

Banerjee, B. (2008). Necrocapitalism. City Research On Line. Recuperado de http:// openaccess.city.ac.uk/6088/

Castro, E. (2004). El vocabulario de Michel Foucault. Un recorrido alfabético por sus temas, conceptos y autores. Bernal, Argentina: Universidad Nacional de Quilmes.

Comisión Nacional de Derechos Humanos (CNDH). (Mayo de 2016). Informe especial sobre desplazamiento forzado interno (DFI) en México. México: Autor.

Comisión Interamericana de Derechos Humanos (CIDH), Organización de los Estados Americanos (oEA). (31 de diciembre de 2015). Situación de los derechos humanos en México. Recuperado de http://www.oas.org/es/cidh/informes/pdfs/Mexico2016-es.pdf

Correa-Cabrera, G. (2015). Desigualdades y flujos globales en la frontera noreste de México: los efectos de la migración, el comercio, energéticos y crimen organizado transnacional. Canadian Journal of Latin American and Caribbean Studies, 40(3), 326-350.

Das, V. (2008). Sufrimientos, teodiceas, prácticas disciplinarias y apropiaciones. En F. A. Ortega (Ed.), Sujetos del dolor, agentes de dignidad (pp. 437-458). Bogotá, Colombia: Universidad Nacional de Colombia, Universidad Nacional de Colombia sede Medellín, Pontificia Universidad Javeriana.

De Génova, N. (2002). "Migrant Illegality" and Deportability in Everyday Life. Annual Review of Anthropology, 31, 419-447.

Estévez, A. (2013a). The Biopolitics of Asylum Law in Texas: The Case of Mexicans Fleeing Drug Violence in Juárez. Norteamérica Revista Académica, 8(Special Issue), 55-81.

Estévez, A. (2013b). The Politics of Death in Mexico: Dislocating Human Rights and Asylum Law Through Hybrid Agents. Glocalism: Journal of Culture, Politics and Innovation, 1(1), 1-28.

Estévez, A. (2015). The Endriago Subject and the Dislocation of State Attribution in Human Rights Discourse: The Case of Mexican Asylum Claims in Canada. Third World Quarterly, 36(5), 1160-1174.

Foucault, M. (1997). Ethics: Subjectivity and Truth (Vol. I). Estados Unidos: The New Press New York. 
Foucault, M. (2004). The Birth of Biopolitics. Nueva York, Estados Unidos: Picador-Palgrave Macmillan.

Foucault, M. (2006). Seguridad, territorio, población. México: Fondo de Cultura Económica.

Giroux, H. A. (8 de abril de 2014). Neoliberalism and the Machinery of Disposability. Truthout. Recuperado de http://www.truth-out.org/opinion/item/22958-neoliberalism-and-the-machinery-of-disposability

Grillo, I. (29 de abril de 2014). Fracking Near the Texas Border has Northern Mexico Trembling. PRI. The World E Global Post. Recuperado de https://www.pri.org/ stories/2014-04-29/fracking-near-texas-border-has-northern-mexico-trembling

Guendel, L. (2009). Políticas públicas y derechos humanos. Principios, enfoques e instrumentos. Madrid, España: Centro de Estudios de Iberoamérica, Comunidad Madrid.

Hernández, S. (27 de enero de 2017). Las 5 cosas que no sabías y tienes que saber de la 'guerra' en el periodo de Felipe Calderón [mensaje de un blog]. Recuperado de https://news.vice.com/es/article/cinco-cosas-no-sabias-tienes-saber-guerra-periodo-felipe-calderon

International Displacement Monitoring Centre (IDMC). (2015a). Global Overview 2015: People Internally Displaced by Conflict and Violence. Recuperado de http://www.internal-displacement.org/library/publications/2015/global-overview-2015-people-internally-displaced-by-conflict-and-violence/

International Displacement Monitoring Centre (IDMC). (2015b). New Humanitarian Frontiers. Addressing Criminal Violence in Mexico and Central America. Recuperado de http://internal-displacement.org/assets/publications/2015/201510-am-central-americas-violence-en.pdf

International Displacement Monitoring Centre (IDMC). (2017). Mexico. Mid-Year Update 2017 (January-June). Recuperado de http://internal-displacement.org/ countries/mexico

Kleinman, A., Das, V. y Lock, M. M. (Eds.). (1997). Social Suffering. Estados Unidos: University of California Press.

Kurzban, I. J. (2014). Kurzban's Immigration Law Sourcebook (14a ed.). Washington, Distrito de Columbia, Estados Unidos: American Immigration Council.

Lallanilla, M. (2015). Facts About Fracking. Live Science. Recuperado de https://www. livescience.com/34464-what-is-fracking.html

Martínez, S. (25 de febrero de 2013). 300 mil desaparecidos y contando. Sinembargo. $m x$. Recuperado de http://www.sinembargo.mx/opinion/25-02-2013/12797

Mbembe, A. (2011). Necropolítica. España: Melusina [sic].

Navarro F., S. y Bessi, R. (6 de diciembre de 2015). Fracking Expands in Latin America, Threatening to Contaminate World's Third-Largest Aquifer. Truthout. Recuperado de http://www.truth-out.org/news/item/33910-fracking-expands-in-latin-americathreatening-to-contaminate-world-s-third-largest-aquifer

Ortega, J. A. (11 de enero de 2010). Cd. Juárez, por segundo año consecutivo, la ciudad más violenta del mundo. Recuperado del sitio de Internet de Seguridad, Justicia y Paz. Consejo Ciudanano para la Seguridad Pública y la Justicia Penal A.C. http://www.seguridadjusticiaypaz.org.mx/sala-de-prensa/58-cd-juarez-por-segundo-ano-consecutivo-la-ciudad-mas-violenta-del-mundo 
Paley, D. (2014). Drug War Capitalism. California, Estados Unidos: AK Press.

Rodríguez, C. (2012). Etnicidad.com: Los recursos naturales, los pueblos indigenas

y el derecho a la consulta previa en los campos sociales minados. Bogotá: Centro de Estudios de Derecho, Justicia y Sociedad, Dejusticia.

Sinnot, E., Nash, J. y De la Torre, A. (2010). Natural Resources in Latin America and the Caribbean. Beyond Booms and Busts? Washington Distrito de Columbia, Estados Unidos: The World Bank.

Soja, E. W. (2009). The City and Spatial Justice. Justice Spatiale/ Spatial Justice, 1(1), 1-5. The United Nations High Commissiones for Refugees (UNHCR). (Junio de 2016). Regional Response to the Northern Triangle of Central America Situation. Recuperado de http://www.unhcr.org/partners/donors/577230ce7/unhcrs-supplementary-appeal-regional-response-northern-triangle-central.html?query=central $\% 20$ america

Valencia, S. (2010). Capitalismo Gore. España: Melusina.

\section{Entrevistas}

Cabot, A. J. (25 de junio de 2012). Coordinadora legal de Las Americas Immigrant Advocacy Center. Texas, Estados Unidos.

Holguín, I. (24 de junio de 2012). Abogada y Directora Ejecutiva del Diocesan Migrant $\mathcal{E}$ Refugee Services, Inc. Texas, Estados Unidos.

Massey, C. F. (23 de junio de 2012). Defensora de derechos humanos y cofundadora del Southwest Asylum \& Migration Institute (SAMI). Texas, Estados Unidos.

Vázquez, S. (31 de enero de 2017). Activista del Comité Estratégico de Ayuda Humanitaria Tijuana. Baja California, México.

Ariadna Estévez

Mexicana. Doctorado en Relaciones Internacionales y Derechos Humanos (University of Sussex, Reino Unido); Maestra en Sociología Política (City University, Reino Unido); Licenciada en Comunicación (Universidad Nacional Autónoma de México [unam]). Investigadora del Centro de Investigaciones sobre América del Norte, de la unAM. Líneas de investigación: biopolítica y necropolítica en América del Norte, migración forzada y asilo en América del Norte, estudios críticos de derechos humanos desde las ciencias sociales, geografías de muerte y espacios necropolíticos, metodología posestructuralista (genealogía, biopolítica, necropolítica y análisis del discurso), estudios críticos de la violencia política, privada y de género. Publicación reciente: con Daniel Vázquez (Coords.). (2017). 9 razones para (des)confiar de las luchas por los derechos humanos. México: Cisan-Flacso. 